\title{
Characterization of the Purchase Decision Process in the Category of Individual Life Insurance with Savings
}

\author{
Ensueño González \\ Institución Universitaria Politécnico Grancolombiano, Bogotá D.C., Colombia, engonzalezpa@poligran.edu.co \\ Carolina Muñoz \\ Institución Universitaria Politécnico Grancolombiano, Bogotá D.C., Colombia, jcmunozlu@poligran.edu.co \\ Oscar Robayo-Pinzon \\ Institución Universitaria Politécnico Grancolombiano, Bogotá D.C., Colombia, osrobayo@poligran.edu.co \\ Sandra Rojas-Berrio \\ Universidad Nacional de Colombia, Bogotá D.C., Colombia, sprojasb@unal.edu.co
}

Received (24-JAN-19); Revised (15-AUG-2019); Accepted (5-OCT-19); Published online (25-OCT-19)

\begin{abstract}
This article's goal is to describe the purchase decision process in the individual life insurance with savings category in Colombia. To this end, the attitudinal and behavioural characteristics of a sample of consumers that own life insurance policies with savings were identified. Given the objective of this report and its temporary scope, the design is of a non-experimental cross-sectional cut. The execution of the methodological strategy required qualitative instruments, and thus, its design was exploratory. Among the main results, it was found that the participants show a tendency to procrastinate, that the purchasing process has a high degree of complexity and that there are four associated factors: situational factors, individual factors, social factors and insurance company marketing activities factors.
\end{abstract}

Key words: Purchase decision, life Insurance, purchase intention, savings

\section{INTRODUCTION}

Life insurance has become a product of increasing importance to the financial market because it provides an array of financial services to consumers and is also an important source of investments in the capital markets [1].

The insurance market plays at least two important roles in stimulating economic growth. First, it operates through a mechanism of risk transfer and compensation. Second, the insurance market influences economic performance although through different channels. However, there are few studies on the role of the insurance market in the economic growth process [1].

Globally, the insurance sector faced a dire economic situation in 2011, as advanced markets contracted 2.3\%, mainly in Western Europe, while the United States posted moderate growth of $2.9 \%$. Japan and Asian countries grew $4.4 \%$. In emerging markets, insurance premiums increased in most cases; overall, however, the outcome was negative due to the strong drop in Chinese and Indian insurance premiums as a consequence of normative changes that disallowed certain distribution channels [2]. Life insurance premiums diminished by $2.7 \%$, as historically low interest rates and expensive natural catastrophes affected the overall results of insurance companies [2]. Market penetration of life insurance as a product reached $2.8 \%$ on average in Latin America, while slightly lower in Colombia at $2.3 \%$. As for the density indicator, life insurance purchase by region is estimated to have reached US $\$ 261$ against only US\$163 in Colombia. In the more advanced countries due to their higher income, insurance purchase per capita is near US $\$ 2,000$ in Europe and above US\$3,500 in North America [3].

In 2011, Latin America was the region with the highest growth $(10 \%)$, but its participation in world insurance premiums remained at a low 3\%. However, it has been increasing at a slow albeit steady rate since the beginning of this decade [3].

The country with the highest participation in the Latin American and Caribbean insurance market in regard to the level of insurance premiums is Brazil with $50.75 \%$. Over half of the insurance market is in this region, followed by Mexico with $14.41 \%$, Argentina with $8.33 \%$ 
and Venezuela with $7 \%$. Colombia is in sixth place with $4.9 \%$ [2].

The Colombian insurance industry, moreover, possesses a low level of penetration and is small compared with the other countries in the region. It has a penetration rate of $2.6 \%$ of GDP, lower than the Latin American average $(3.1 \%)$ and than countries such as Chile (4.7\%), Venezuela (4\%) and Brazil (3.9\%) [4].

The structure of the Colombian insurance market in regards to insurance premium distribution by sector as of 2014 is concentrated mainly in labor risk (25\%), general life insurance (17\%) and cars (12\%) [5]. Within the life insurance sector's $17 \%$, individual insurance has a share of $10 \%$. However, in the last 5 years, the percentage of Colombians who are aware of life insurance and use it as a savings and financial home protection system has increased by $13 \%$ [6].

The penetration of individual life insurance with savings is dependent on income and the financial knowledge of households regarding the importance of protecting the family [6]. Due to a lack of sufficient income, $33 \%$ of urban households would fall into poverty if faced with an event that affected their income. A total of 300,000 households fell into debt or spent their savings due to an unexpected situation, and 54,000 fell behind on tuition payments or even fell into absenteeism [7]. Likewise, Nuñez and Espinosa [8] estimated that 39\% of Colombian households, while not poor, if faced with an income-affecting event, would fall into poverty.

By the end of 2015, Colombia had approximately 1.5 million individual life risks insured $(7.1 \%$ growth over 2014), of which approximately 470,000 corresponded to so-called long-term or traditional products [6].

An individual can use a life insurance policy to fulfill a future goal. However, it will derive from income from a job, pension, lifelong rents or social security. Here, the inheritance the individual wishes to transmit to his heirs is taken into account, which is separated from any wealth related to the above-mentioned income, leading to an optimum strategy in the purchase of life insurance with savings and maximizing the probability of reaching said goal [9]. Although consumer behavior has been analyzed for over 50 years in the financial services sector [10], [11], [12], [13], attention to the characteristics of insurance consumer behavior has been rather limited. In these studies, a common interest can be found in the analysis of consumer demand without taking into account the behavior of the consumer, as shown by research conducted by Kunreuther and Pauly [14], who studied the anomalies in insurance consumer demand.

On the other hand, there is a stream of studies focused on how firms can successfully include their clients in innovation processes at the level of both tangible products and services. In this sense, it is assumed that the customer is at the center of the process of developing a new product, for which it is essential to understand their expectations and requirements. However, the company must carefully design the process through which the client will be included in the development of the new products, something that if achieved is associated with greater chances of success in the market. [15].

One of the most effective ways to achieve this link between the consumer and the company is through cocreation, which starts from the principle that the best possibilities for innovation are hardly found by resorting solely to the company's internal resources. That is, when the consumer experience begins to be taken into account as a central element in value creation and innovation [16]-[18]. In this new context, the most important actor or stakeholder for an organization becomes the consumer, in particular those who show a favorable attitude for the evaluation of their own experience and decide to contribute ideas within a product improvement process. These consumers are known as prosumers, by the combination of the terms "consumer" and "producer" and are characterized by helping to create value not only for them but for all other consumers. [19]. It is relevant then, to inquire into consumers of life insurance with savings about how their purchase process occurs and what kind of experiences and factors influence their decision making.

Based on the previous considerations and given that there are no tools that enable us to analyze the purchase decision process for this type of service in the related literature, this study poses the following question: What characterizes the purchase decision process in the individual life insurance with savings category for men and women of socioeconomic levels 4,5 and 6 in the city of Bogota?

The main goal of this study is thus to describe the purchase decision process in the individual life insurance with savings category in Colombia. This study was oriented on the basis of the following specific objectives:

- Identify the attributes relevant to the consumer associated with the intent of purchase in the individual life insurance with savings category.

- Explore the possible relationship between the various variables associated with the purchase decision process in the individual life insurance with savings category.

- Describe the attitudinal and behavioral characteristics of consumers in the purchase decision process in the individual life insurance with savings category.

- Analyze if there are differences in the purchase decision process in the individual life insurance with savings category related to a set of demographic variables.

\section{LITERATURE REVIEW}

Although there have been a number of advances in the identification of factors influencing the decision-making of insurance consumers, particularly with regard to life solutions [20], [21], [22], these studies have focused on the influence of socioeconomic, demographic [21], [22], and consumer satisfaction factors that lead to a higher or lower probability of purchase decision. Additionally, several of these studies were conducted with 
populations not representative of the insurance market [23]. How a consumer selects an insurance alternative has thus not been identified, nor has it been determined which are the attributes that are considered at the moment of evaluating different alternatives or how consumers select among them with regard to their intent to purchase [23].

In this respect, there are approaches from other areas to the study of products of different categories for which the consumer decision process is complex. For example, in Liu and Chen, the key factors that influence the adoption behavior of the users of an intelligent medical terminal were evaluated, finding the presence of five dimensions and ten criteria as part of the decision process, among which the environmental and safety dimensions are remarkable [24]. Another trend in the literature has focused on processes within companies, from approaches such as evolutionary economics, according to which, each organization develops its own genome, known as routine. It consists of the whole of strategies for the development of new products, innovation, the way of doing business and human resources management policies, which consolidate over time and make each company different from the others in these aspects. Specifically, Yoon, Jung, Lee, Kim and Kim studied the innovation strategies applied by various manufacturing firms in the smartphone category, finding interestingly that a company's market share tends to increase when there is an improvement in the current characteristics of these devices instead of adding new features [25]. That is, the firms that apply imitation or incremental innovation are the ones that have the greatest dominance in this market.

Whereas, social learning theory, also known as cognitive stimulus theory, claims that people learn what to do from the behavior of others and that there is a tendency to learn from people who are significant to the individual, to whom these are role models. The individual thus seeks to reflect their behavior [26].

Prior studies of consumer behavior have analyzed several theories, among them the prospective theory, which is considered the best possible description of how people assess risk and make decisions in conditions of uncertainty and is an important tool in analyzing the decision-making of consumers with regard to insurance [27]. Thus, the cognitive models that intervene in the purchase process are important. Although the implications of prospective theory for insurance purchase are not fully clear, cognitive biases hinder rational decision-making. Understanding how these biases influence decision-making could help insurance companies to improve their products and the consumer's purchasing experience [27]. Several of the key cognitive biases related to insurance purchases are analyzed below.

\subsection{Biases, procrastination and current state}

Often people postpone making difficult decisions because they involve unpleasant debates and/or thoughts. Procrastination can also be related to the fear of loss in that people sometimes delay decision-making to avoid emotional stress and the responsibility involved in making a wrong choice. Procrastination is, in fact, an important obstacle to the purchase of an insurance policy. It is a consequence of the fact that the consumer does not completely understand the purchasing process, that it implies many difficult tasks and that it requires considerable knowledge. Often the purchasing process is long, particularly when it involves a medical subscription, as is the case in the purchase of individual life insurance with savings when the individual's health is not optimal for the purchase of life insurance [27].

Perceived risks are relevant in the case of complex and new purchases, where these may arise from many sources and affect the purchase decision and the relationship with clients [28]. There are five risks associated with purchases: performance risk, psychological risk, financial risk, time loss risk, and physical risk [29].

\subsection{Inconsistent preferences through time}

In experimental research, people often reveal preferences that are not consistent through time. When asked "Would you rather have a dollar today or three dollars tomorrow?" or "Would you rather have a dollar in a year or three dollars in a year and a day?," among offers, a sizable portion of people prefer the lower amount today, but they will in turn wait another day in a year to receive the greater amount. In short, people apply a "hyperbolic discount" of sorts, in which the perceived value drops quickly for short delays and slowly for longer delays [27]. Risk aversion is an attribute most people have and is widely recognized within the field of aversion to loss, which, while sounding like risk aversion, is in reality a type of complex behavior whereby people express both risk aversion and the risk of the search behavior. Risk aversion is not only the wish to reduce risk; it involves a total abhorrence of loss.

The insurance consumer's behavior is substantially influenced by several factors [30], such as:

1. Factors associated with insurance companies' marketing activities: among which we can mention the impact of the marketing policy of insurance companies, product characteristics and distribution of insurance services, activities related to paid premiums and the payment options offered, activities related to sales staff influence, coverage provided, forms of payment and distribution channels.

2. Individual factors: age, gender, life stage, employment, financial situation, education level and attitudes.

3. Social factors: natural, demographic, economic, legislative and technological factors related to the socioeconomic characteristics of consumers, the culture, social class, beliefs, reference group and family.

4. Situational factors: towards the product and the decision-making process prior to the purchase of the insurance policy, during the acquisition of the policy and after the acquisition of the policy. 
It has also been found in studies in very different product categories, external conditions that influence consumer decision making. A research conducted in China investigated consumers of the Volkswagen brand for their responses to the information on the risk of using certain models of vehicles and their behavioral intentions regarding the brand, just after the outbreak of a media crisis from cases of critical failures of some vehicles that led to the occurrence of serious traffic accidents. The results showed that prior knowledge of the product that customers have plays an important role in how they responded to the crisis. Those who had more knowledge, perceived a lower risk against continuing to use the vehicle, as long as they had access to as much information as possible about the technical failures identified. This was in turn associated with a greater intention to search and process information as well as a positive behavioral intention towards the firm. [31].

\subsection{Consumer decision-making process}

Consumer behavior is defined as the behavior shown by consumers as they seek, buy, use, evaluate and discard the products and services that they consider satisfy their needs [32]. Consumer behavior as described by Shiffman is focused on the way individuals make decisions to spend or invest their resources, time, money and effort in articles related to consumption. This includes what they purchase, why they purchase it, when they purchase it, where they purchase it, how often they purchase it, when they use it and how they evaluate and perceive it afterwards.

To understand the behavior of consumers in the context of the service industry, a causal matrix has been developed that is based on the work of the following authors: Dweyr, Schurr and Oh [33] and Emerson [34], whose focus is the "ideal worker type" methodology.

Huber [20] sought to characterize phenomena in large groups and to identify the most significant traits of social life that facilitate the construction of hypotheses regarding reality. This is consistent with the work of [35], who described attitudes and results that motivate the behavior of consumers.

With respect to the interactions of consumer-buyers, it is possible to identify two main factors that motivate and determine the purchase decision: participation (involvement) and uncertainty (trust) with respect to the purchase. When analyzing these factors, it is possible to construct one of the two dimensions of the consumer behavior matrix that offers increased knowledge regarding consumer interaction (see Figure 1).

This matrix describes the purchase or hiring of available alternatives for consumers. By structuring their interactions in terms of product and service acquisitions, each quadrant represents a different combination of participation and uncertainty, determined in large part by the perceptions of risk and influenced by the complexity of the acquired product and the safety of the result associated with this product [36].
The advantage of the consumer behavior matrix is that it is considered an approach that leads to a deeper understanding of the consumer's purchases and the behavior of the individuals at the time of purchase [36].

\subsection{Forms of consumer behavior}

The model describes four ideal types of consumer behavior:

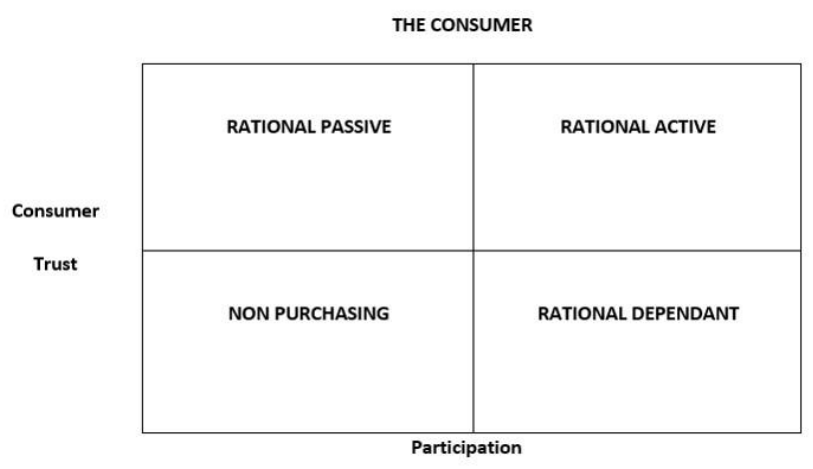

Figure 1.

Source: Authors' elaboration based on Shostack [36]

\subsubsection{Rational Passive}

In this quadrant, consumers are characterized by low levels of engagement with the insurance company, although they are fully aware of the characteristics of the products. Given their low participation levels and limited perception of uncertainty, these consumers can be described as "passive" in that they will have repetitive interactions without actively seeking other options or alternatives.

\subsubsection{Rational Active}

The participation and the contact of the consumers in terms of the dimensions of the control process are high and so is their trust in terms of the complexity of the product and the certainty of the result.

These are consumers with the capacity and inclination to act, who carefully consider their purchase decisions in all environments.

\subsubsection{Rational Dependent}

In this quadrant consumers are highly involved, but they lack control due to the product's complexity and the uncertainty of the final result, which reduces trust. These consumers will request advice and help from third parties.

\subsubsection{Non Purchasing}

This quadrant describes consumers with no engagement with the product or service and who do not have the skill or trust necessary to have initial purchase intent. 
Individuals who leave great sums of money deposited instead of buying financial services that could generate greater yields are an example of this behavior.

Consumer behavior highlights the importance of performing a study to define which factors are associated with the purchase decision process in the individual life insurance with savings category for men and women over 25 with a socioeconomic level of 4,5 or 6 in the city of Bogotá [37].

\section{METHODOLOGICAL STRATEGY}

Based on the reviewed literature from which this study's question arose, a pragmatic approach appeared necessary. Given that the objective of this work and its temporary scope was of a non-experimental crosssectional cut, the execution of the methodological strategy required a qualitative instrument, and thus, its design was exploratory [38]. From the data analysis perspective, an inductive exercise was assumed, considering the grounded theory as an appropriate research strategy to describe ontologically - or from its nature - a phenomenon such as the purchase decision. [39]. Below, several relevant aspects of this study are described, including participants, data collection and data analysis.

\subsection{Participants}

The approach to participants followed the suggestions indicated in [40], in which it is understood that qualitative research does not intend to correlate variables, but to verify the fulfilment of inclusion, exclusion and elimination criteria in the participants and to achieve a deep description of them from informationrich cases [41].

Each phase included ten participants. In phase 1, the data collection instrument was approved. In phase 2, the instrument was applied to each participant in depth. The instrument was composed of open questions. For clarity, it should be mentioned that individuals who do not purchase insurance policies were not taken into account in this study.

The sampling technique applied in each phase was as follows:

Phase 1: A non-probabilistic convenience sampling was performed for the approval of the instrument with open questions on both men and women over 18 from social classes 4, 5 and 6. As mentioned above, life insurance comprises $17 \%$ of premiums in the insurance sector, of which the individual life category has a $10 \%$ share. However, only $4 \%$ of these $10 \%$ correspond to individual life. It was for this reason that the sample was taken from these social classes [6].

Phase 2: In this phase of the study, the sample was selected via non-probabilistic convenience sampling, selecting 10 insured individuals with an individual life with savings policy with the following condition: $50 \%$ men and $50 \%$ women. Below is a table that summarizes the demographic characteristics of the participants:

Participant

\begin{tabular}{|c|c|c|}
\hline Participant & Age & Gender \\
\hline Interviewee 1 & 50 & Male \\
\hline Interviewee 2 & 45 & Male \\
\hline Interviewee 3 & 46 & Male \\
\hline Interviewee 4 & 53 & Male \\
\hline Interviewee 5 & 27 & Female \\
\hline Interviewee 6 & 30 & Female \\
\hline Interviewee 7 & 55 & Male \\
\hline Interviewee 8 & 45 & Female \\
\hline Interviewee 9 & 58 & Female \\
\hline Interviewee 10 & 55 & Female \\
\hline
\end{tabular}

\subsection{Data collection and analysis}

In-depth interviews were conducted to collect personal experiences through open questions. The interviews followed a common guideline that focused on the subjects that required exploration. First, participants were presented with an informed consent requesting authorization to record the interview and process the information.

Secondly, following the structure recommended in the previous literature on the subject [42], [43], the background of the interviewee, the main themes for the inquiry, as well as the perceptions, attitudes and behaviors of the interviewees were reviewed. Therefore, after a brief introduction of the interview process, the conversation started with a general question about a typical day in the life of the interviewee, and from there, different topics - main themes - were explored according to previous literature, [30], such as individual aspects, marketing factors, social aspects, situational aspects, decision and purchase. The interview guide appears in Appendix 1.

Although the literature recommends having at least 30 minutes per in-depth interview to be considered as such [42], the average duration of the interviews was 75 minutes, since the purpose of the research was to recognize and build the characterization of the phenomenon in depth.

Thus, with each interview we looked for what [40] describes as a process theory that accounts for the events and processes that connect them, an approach that involves the understanding and analysis of the processes of which some events influence or lead to others, same procedure that is recommended for "local analysis of particular individuals, events, or settings than on establishing general conclusions" [44, p. 38]. In this way, it was possible to approach interview to interview until reaching the saturation level in questions such as: why, how, to what extent and under what conditions. These aspects were described with the aforementioned participants, especially when the sampling strategy was sampling to address initial research questions [45], valid in the analysis exercise, typical of the grounded theory.

With the purpose of analyzing the information, the interviews were transcribed literally and the procedure to analyze them contemplated the open, axial and selective coding that is recommended in the grounded theory. [46]. 


\section{RESULTS}

Four family codes or theme areas characterizing the decision-making process were identified: situational factors, individual factors, insurance company marketing activities factors and social factors. Each family code has sub-codes that are grouped on the

basis of similarities in meaning and sub-relation to the thematic area. The relationship between the codes is visually summarized and represented by red arrows in the figure below as well as in spontaneous quotes from the interviewees.

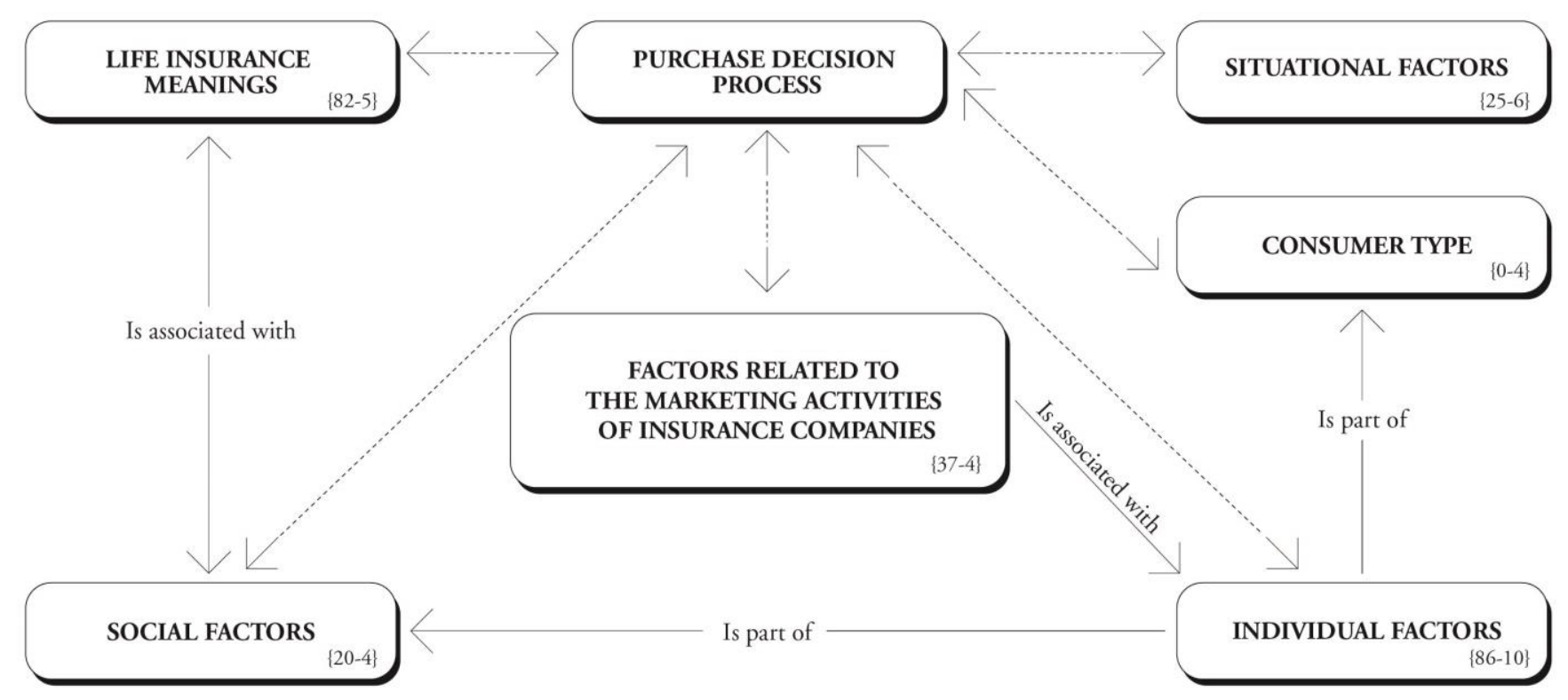

Figure 2. Summary of the networks between the codes that are found in the family.

Source: Authors' elaboration based on the cross-sectional non-experimental interviews.

The results show that the purchase decision of a consumer in the individual life insurance with savings category is determined by four types of factors: situational factors, individual factors, social factors and insurance company marketing activities factors.
Inside this family, consumer behaviors that lead to the identification of possible consumer types were found: rational active, rational passive and rational dependent, which agrees with the proposition of Shostack [36]. 


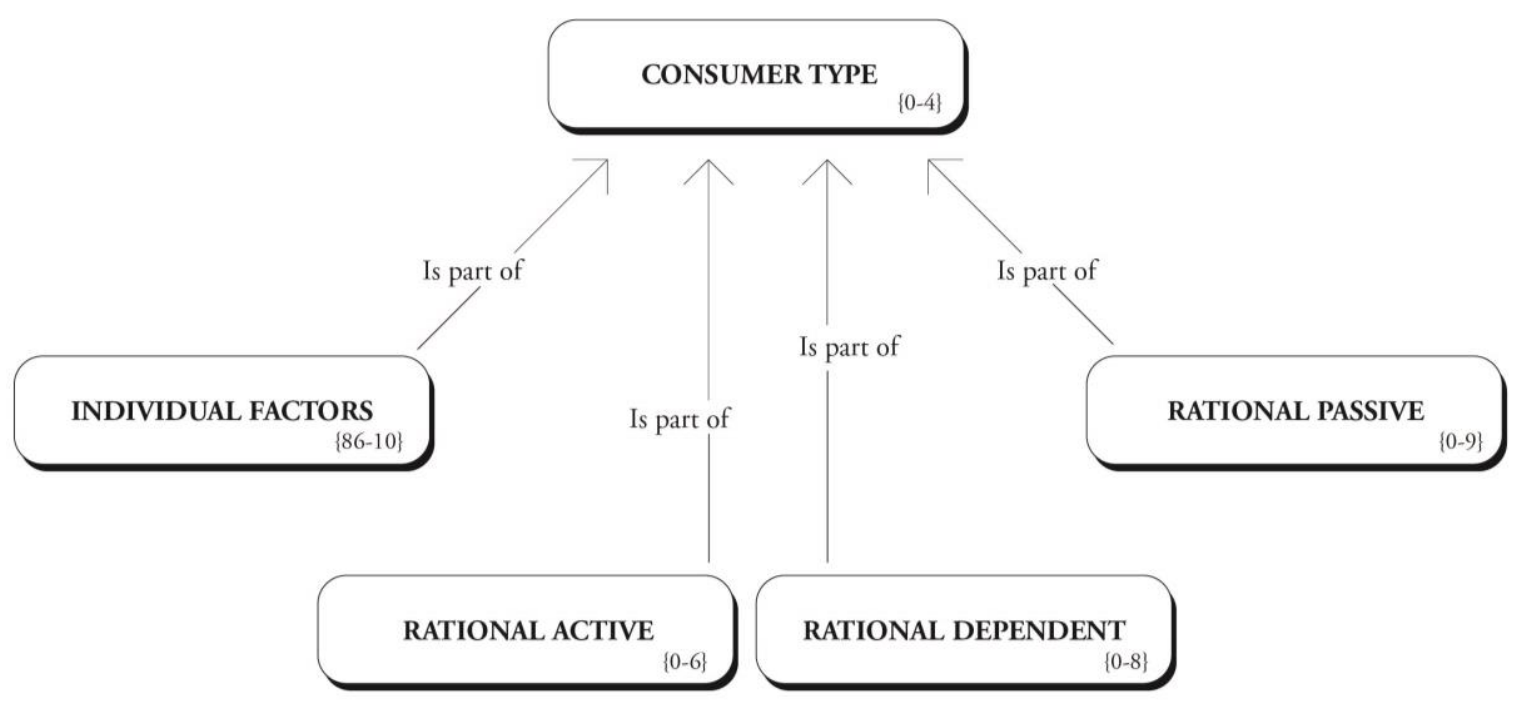

Figure 3. Summary of the networks between codes that are found in the Consumer Type Family.

Source: Authors' elaboration based on the cross-sectional non-experimental interviews.

The study proves that, as stated by Shostack [36], there are in fact several types of consumers, each with their own influences and interests present at any stage of the decision-making process. A concrete example of a rational active customer can be observed in the case of the interviewee N 5:

"The perception most people have is that money is lost, is to throw a bunch of money away. I recover the money I paid, I'm protected and I recover the money I paid, and if a have to retire early, I get most of the money I paid back, they take away a bit of it and that is to pay the protection they gave me, uhhh, that means that it's good for me. Moreover, that money I pay has a yield; it's like an investment fund. Third, it allows me to think about objectives, of survival, as I told you, not just in death". (Woman, Age: 27).

And interviewee N 3: "I finish paying for insurance, and when I do, they return all the premium I've paid and I get a yield, then I have a real growth of the money I paid, and I was protected for free; that's the best thing that can happen to you, all for free hahaha". (Man, Age: 46). 


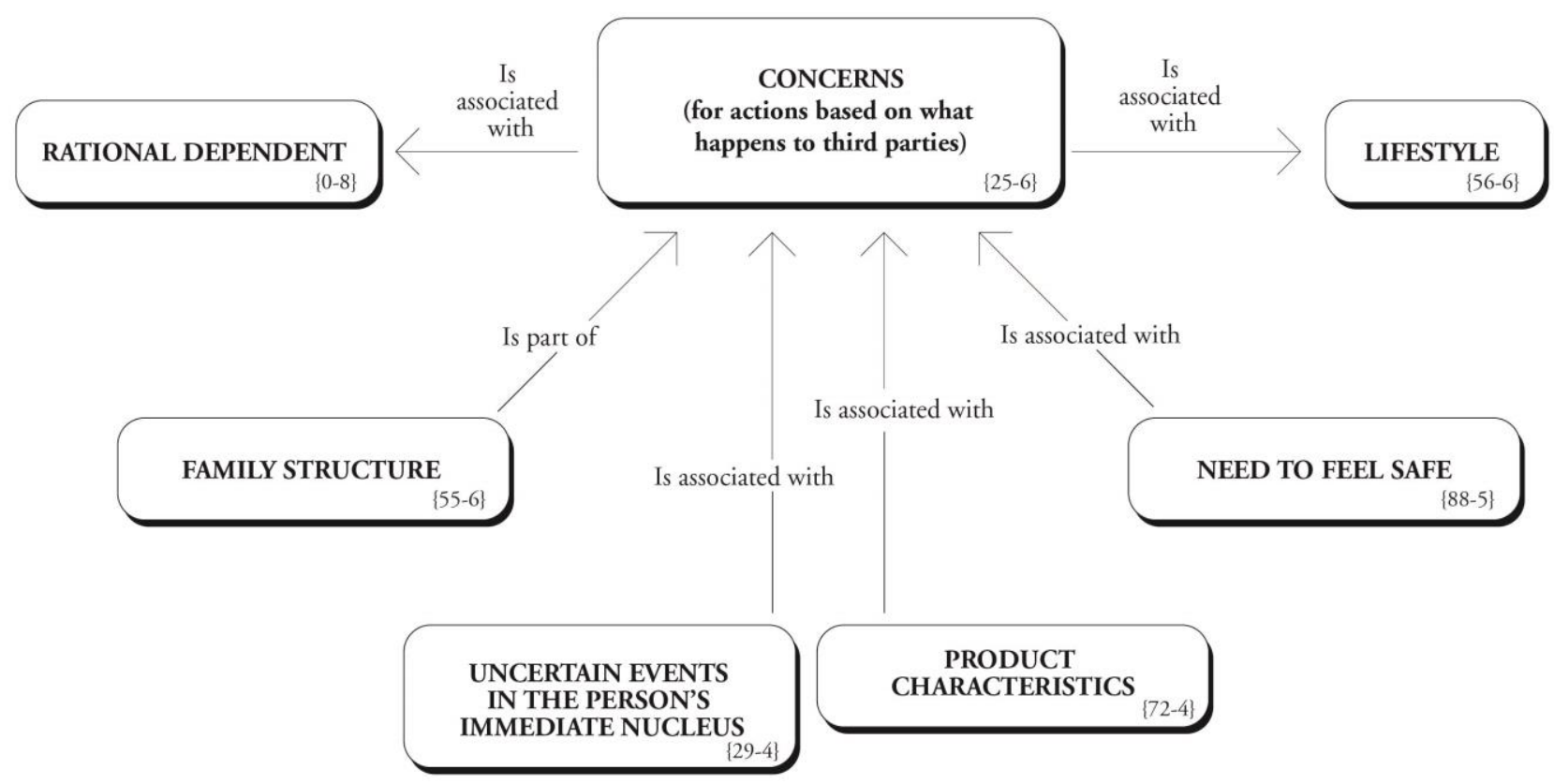

Figure 4. Summary of the networks between the codes that are in the concerns code (for actions based on what happens to third parties).

Source: Authors' elaboration based on the cross-sectional non-experimental interviews.

Consumer perception at the decision-making moment is in many cases influenced by their social environment and individual factors, as can be seen in the case of interviewee $\mathrm{N}$ 4:

"Have you ever lived situations of a relative or acquaintance that have led you to buy insurance?
Answer: yes, my dad was murdered when I was 10 years old, being the eldest of my 3 brothers".

"Suddenly a friend spoke to me and said: Brother, be careful, you never know, take a small one". (Man, Age: 53) 


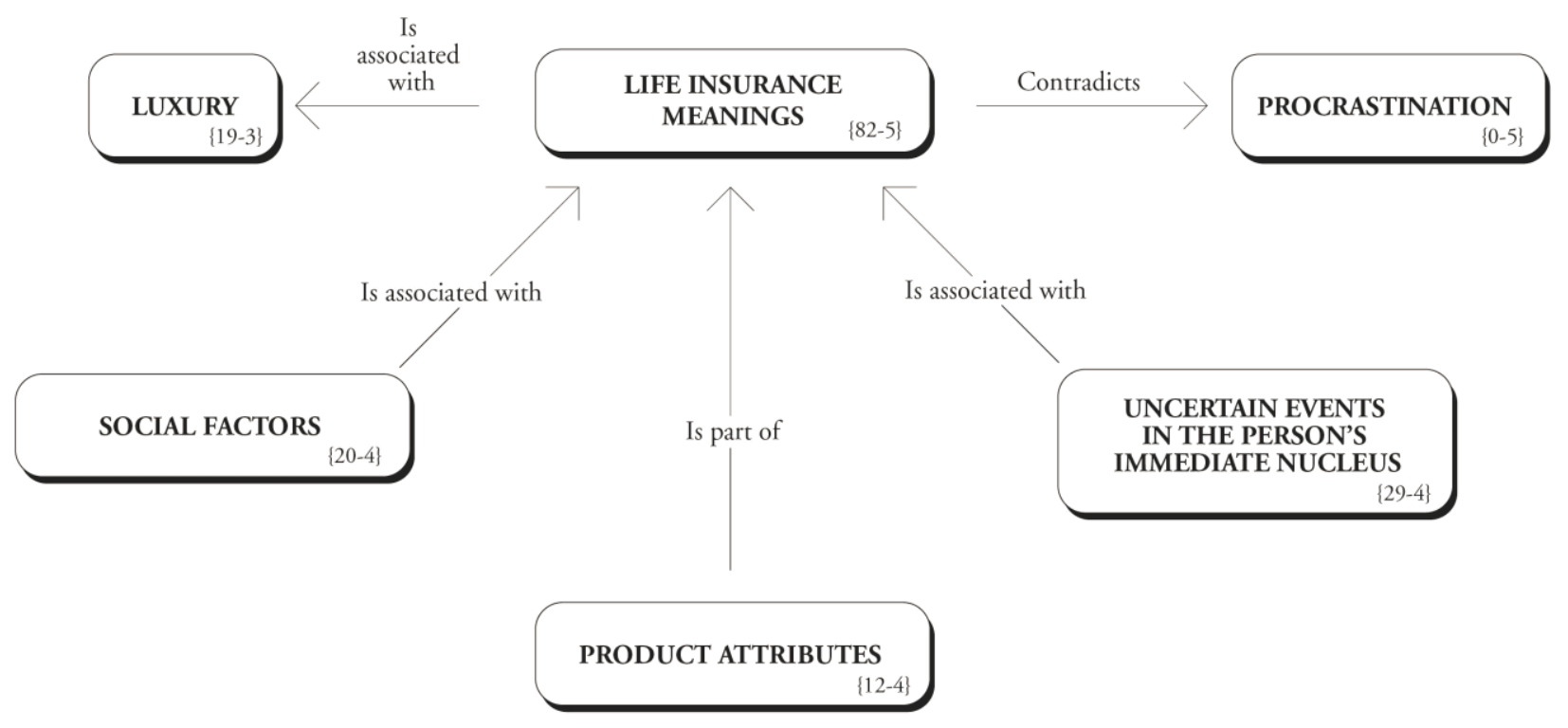

Figure 5. Summary of the networks between the codes that are in the life insurance definitions family.

Source: Authors' elaboration based on the cross-sectional non-experimental interviews.

The study reveals that the decision to purchase life insurance with savings shows the financial vulnerability of the household or the household's sensitivity to the loss of income as a result of the death or disability of the head of household.

It was found to be a common factor among the participants that at a certain point in the purchase decision process, they engaged in procrastination. They considered the decision to acquire life insurance as a complex task first due to the amount of information available and second because they have other financial obligations. This can be seen in the response of the interviewee $\mathrm{N} 1$ :
"We always live in uncertainty; you leave the house not knowing if you'll come back, so you don't have to think that buying groceries is all there is. Responding is providing a life plan that must be sustainable even if I'm not there; so, to me it's what must be, responsibility". (Man, Age: 50).

And interviewee N 3: "This society does not know where it's headed, economically speaking, nor in the family nor anywhere else. If I make money, I have to protect that source of income; I can't ask for income redistribution if I'm not capable of protecting my own family's income, as this would be an unviable society, hahahaha". (Man, Age: 46). 


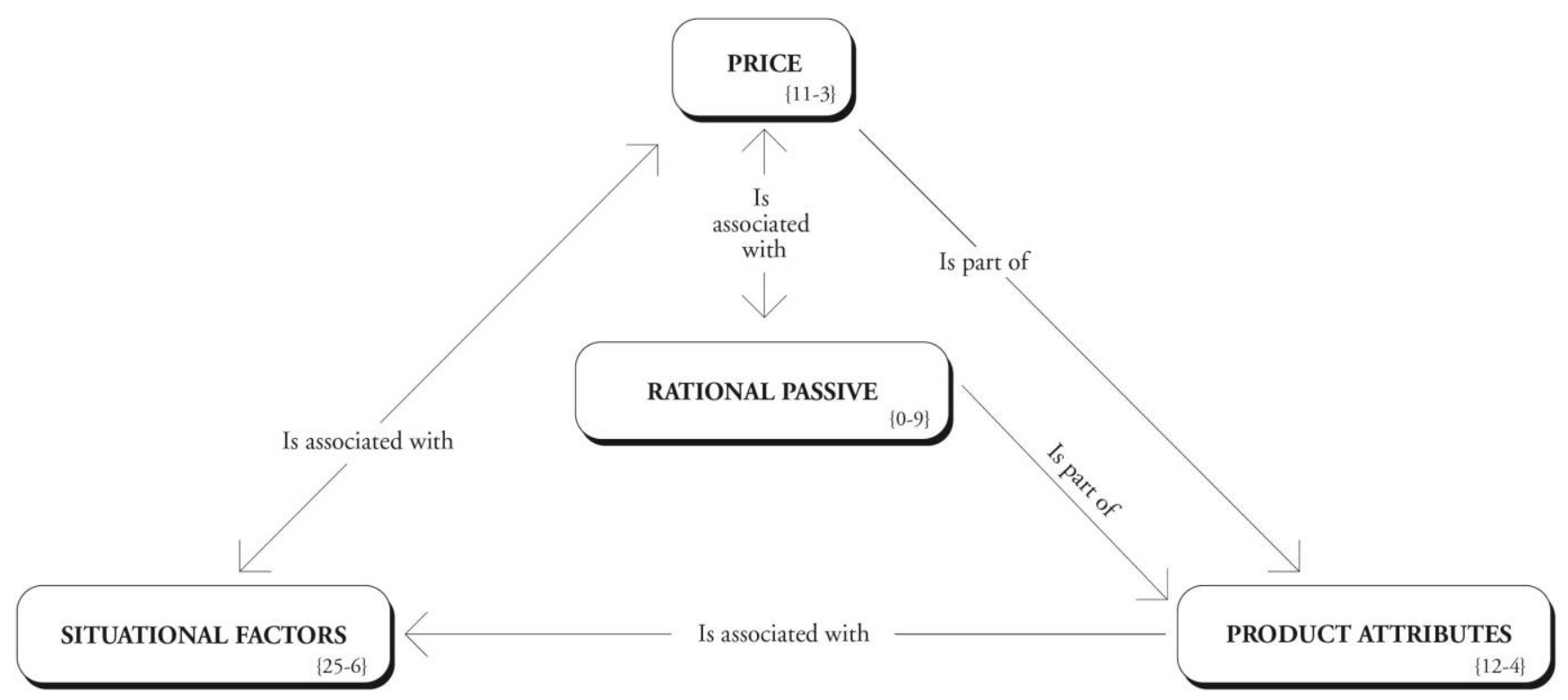

Figure 6. Summary of the networks between the codes that are found in the price sub-code

Source: Authors' elaboration based on the cross-sectional non-experimental interviews.

Consumers recognize the importance of individual life insurance with savings, which is why they acquire this product. Additionally, Fasecolda [6] confirms that life insurance is considered cheap when compared to the benefits it provides based on his research. This is clearly expressed in the response of the interviewee $\mathrm{N}$ 9:

"At the beginning, it was the cost to benefit ratio; so, what good is it for me, and how will I benefit? I mean, at the beginning, as I was telling you, the benefit I sought was to protect my family, then I wanted to see if I truly got that benefit, uhm, and how much would it cost. It was the cost to benefit ratio; after that, the benefit slowly became more important than the cost, so I kept it until the program expired". (Woman, Age: 58) 


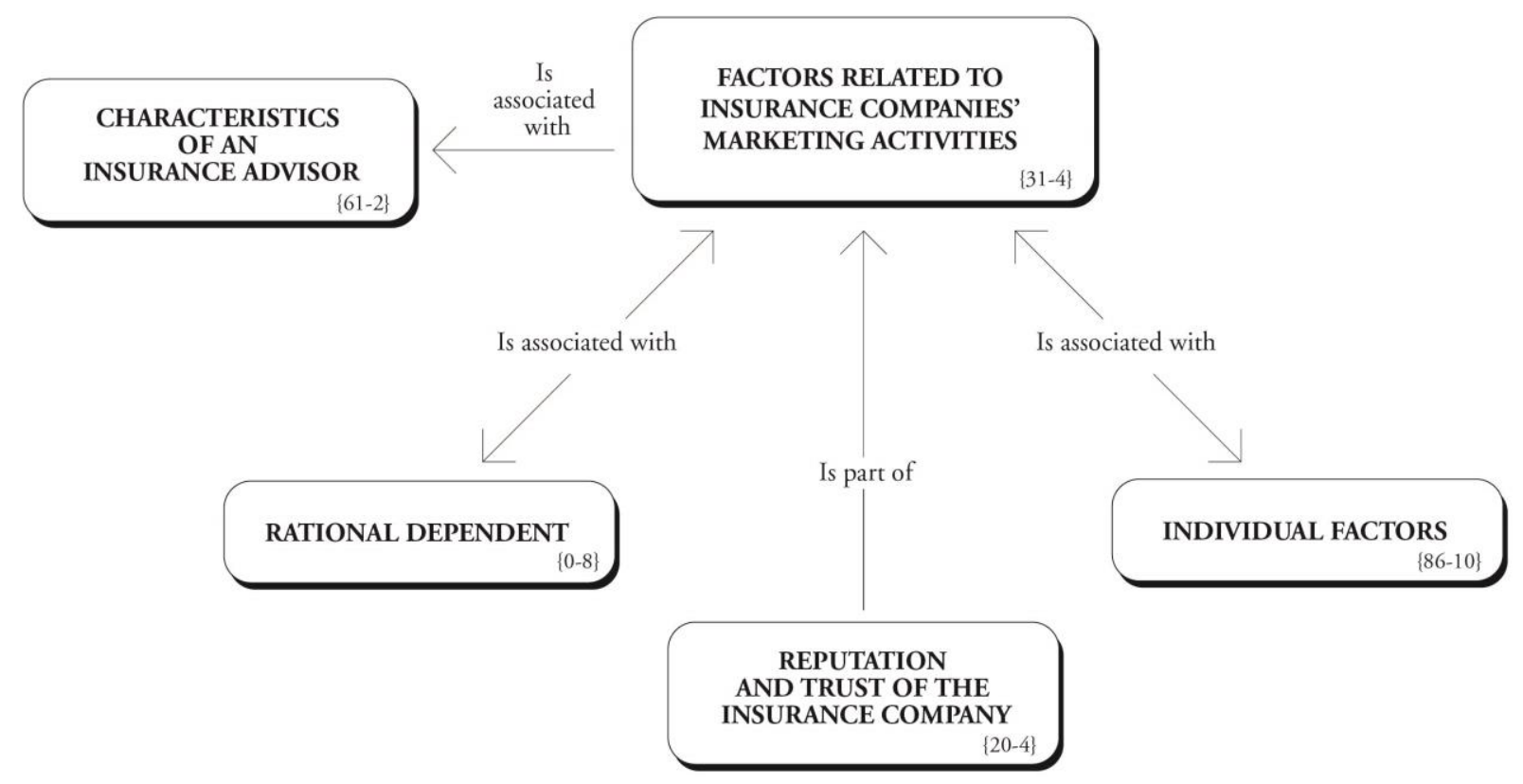

Figure 7. Summary of the networks between the codes that are found in the marketing sub-code

Source: Authors' elaboration based on the cross-sectional non-experimental interviews.

It was found that several of the interviewees presented favorable experiences of the purchasing process, which influenced the repurchase process. The remainder, although their insurance had not expired yet, claimed that they would renew the product.
Based on the interviews, the purchase decision process was established, including several influential factors, as shown in figure 8. 


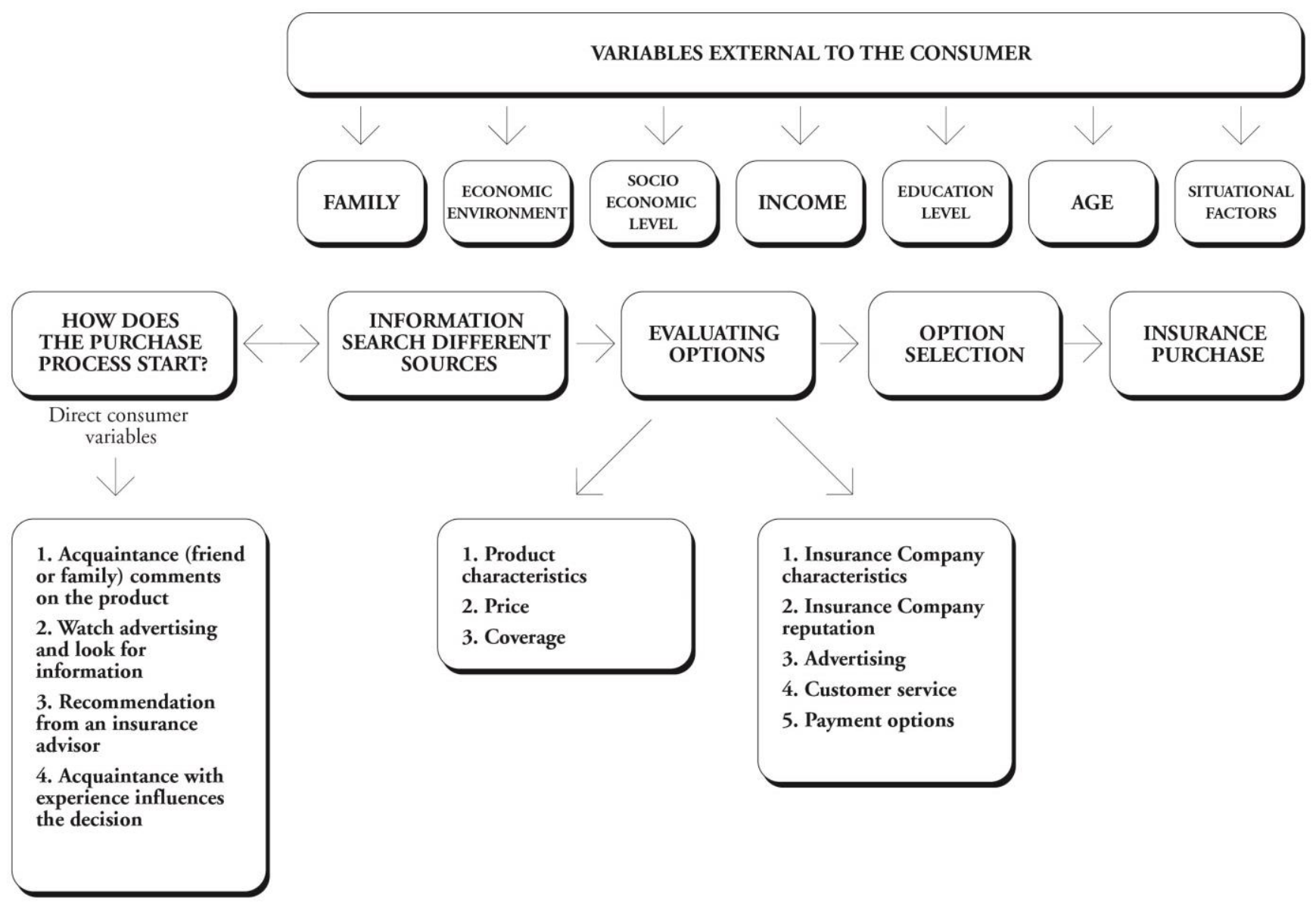

Figure 8. Decision-making process for the purchase of life insurance

Source: Authors' elaboration based on the cross-sectional non-experimental interviews.

Before arriving at the purchasing process, there are important external conditions that lead an individual to a purchase decision process. Variables such as age, gender, socioeconomic level, environment or place of residence, place of living, family and income determine the purchase process. In a number of cases, it is due to friends or relatives who lead the consumer to inquiry as a result of the insurance company's publicity, via mass media or through an advisor, to determine if the policy really is a solid investment. Through this commercial advisor, the client receives information that provides him the opportunity to compare in the market what might be the best choice, verify the characteristics of the product, coverage and prices, analyze the best option and make the decision, with the accompanying assurance of being advised by an experienced insurance counselor with a trustworthy insurance company. This is where the final decision to acquire the insurance policy originates.

\section{DISCUSSION}

This study corroborates the claims of Hou, Cheng and $\mathrm{Yu}$ [1] and Fasecolda [6], stating that insurance (product significance) and particularly an insurance policy's attributes coincide not only as an important source of investment in the capital markets but also as a life investment and source of goal achievement for participants.

It is confirmed that although there have been a number of advances in the identification of factors that influence decision-making among insurance consumers, particularly in life solutions [20], [21], [22], these have focused on the influence of demographic factors [22] and socioeconomic factors [21], [22], but have not taken into account marketing factors that lead to higher or lower odds of purchase decision.

Conversely, the study shows that it is a challenge for insurance companies to generate trust and to transmit knowledge regarding life insurance to clients, as suggested by Kasirajan [21]. Organizations must generate options in the various channels in order to create awareness of life insurance with savings by their clients. In this sense, the goal is to generate the need and show the insured individuals that the company will support them.

The opportunity to increase contact with potential clients and provide them sufficient knowledge to recognize the importance of life insurance arises [6]. 
Likewise, at the moment of making the decision to purchase life insurance with savings, the company is of vital importance, and although not a main factor, the decision is influenced by the awareness and coverage generated by the insurance company.

Future research should evaluate possible factors impacting the purchase decision, where the process is reflected in terms of factors and relationships from a quantitative perspective. Additionally, studies should design a research model that reflects the service provided by the insurance company at the moment of repurchase, to validate what led the customer to make the repurchase, namely, to assess customer loyalty. Likewise, future work could focus on one of the limitations of this study, investigating the differences between current owners of life insurance with savings policies and individuals who never owned one, exploring what could be the motivating and inhibiting factors for these types of consumers.

Conclusions: There are several theories with regard to consumer behavior that allow us to understand such behavior from different perspectives, including social, cognitive, attitudinal and psychological. All of these focus on how the consumer acts when exposed to various stimuli and on the consumer's disposition to execute certain behaviors. The demographic variables associated with the ownership of an insurance policy are education level, gender, income and marital status.

It was found that the insured interviewees exhibited the need for an advisor to provide counsel in all issues related to insurance services, emphasizing that the advisor must be competent and provide quality service. It is necessary to simultaneously increase the financial education of the Colombian people and to strengthen the practices of insurance companies in demonstrating the benefits of insurance policies.

All the owners of insurance policies who were interviewed exhibited a perceptive attitude towards insurance because to them, it represented a good investment. Additionally, they highlighted the product's attributes, indicating that the aim is not just to obtain insurance but to be certain that they can save instead of spending to achieve goals at the individual or family level. One of the aspects the insured interviewee considered before making a decision regarding life insurance with savings was cash flow, to be able to maintain coverage over time. This means that consumers take into account an approximate projection of how much their income should be in order to meet the quota, thus minimizing the risk of being left without coverage of the policy for a possible non-payment. This result has important implications for marketing managers regarding the empirical approach that can be given in future research that place potential clients in different experimental scenarios, controlling variables that are significant in such projection of the cash flow by customers. This information will improve the advisory process by the companies sales teams, a factor that also proved to be important in this research.

On the other hand, the study shows that the process of purchasing a life insurance with savings policy is the same for both genders, as there was no perceivable difference between them. The diversity among Colombian consumers with regard to purchase decisions is a function of their income, education level and marital status. Furthermore, the results show that it is important for a family with children to have life insurance with savings because it allows them to reach future goals, such as the children's education.

The results of the study could represent a source of information in the development of strategic marketing plans intended to develop tactics to grow life insurance purchase intent, maximizing and focalizing marketing resources. Based on the above, it is necessary to consider the implementation of periodic marketing studies to evaluate the evolution of this phenomenon and discern any changes, providing opportunities or generating alerts for insurance companies.

\section{REFERENCES}

[1] H. Hou, S.-Y. Cheng, and C.-P. Yu, "Life Insurance and Euro Zone's Economic Growth," Procedia - Soc. Behav. Sci., vol. 57, pp. 126-131, 2012.

[2] I. Fan, T. Seller, and D. Stalb, "Sigma No. 3-12: World insurance in 2011: Non-life insurance branch readies for take-off," Zurich, Switzerland, 2012.

[3] R. Junguito, M. J. Vargas, and D. Pinzón, "Seguros en América Latina. [Insurance in Latin America]," Rev. Fasecolda, vol. 147, pp. 23-26, 2012.

[4] Fasecolda, "Informe de sostenibilidad del sector asegurador colombiano 2015," 2016.

[5] Fitchratings, "Sector de Seguros en Colombia: Desempeño 2009 y Perspectivas 2010-Calificación de Riesgo," 2010.

[6] Fasecolda, "La demanda de seguros de vida en Colombia: Una visión integral," 2015.

[7] DANE, "Colombia: Cifras," 2014.

[8] J. Nuñez and S. Espinosa, "No siempre pobres, no siempre ricos: vulnerabilidad en Colombia [Not always the poor, not always the rich: vulnerability in Colombia]," Universidad de los Andes, Documentos CEDE 003275, 2005.

[9] E. Bayraktar, D. Promislow, and V. Young, "Purchasing Life Insurance to Reach a Bequest Goal," Insur. Math. Econ., vol. 58, no. 1, pp. 204-216, 2014.

[10] A. Beckett, P. Hewer, and B. Howcroft, "An exposition of consumer behaviour in the financial services industry," Int. J. Bank Mark., vol. 18, no. 1, pp. 15-26, 2000.

[11] T. Harrison, "Editorial: Understanding the behaviour of financial services consumers: A research agenda," J. Financ. Serv. Mark., vol. 8, no. 1, pp. 6-10, 2003.

[12] L. E. Willis, "Against Financial Literacy Education," Iowa Law Review, U of Penn Law School Public Law Research Paper No. 08-10, 2008.

[13] A. Capuano and I. Ramsay, "What Causes Suboptimal Financial Behaviour? An Exploration of Financial Literacy, Social Influences and Behavioural Economics," U of Melbourne Legal Studies Research Paper No. 540, 2012.

[14] H. Kunreuther and M. Pauly, "Insurance Decision-Making and Market Behavior," Found. Trends Microeconomics, vol. 1, no. 2, pp. 63-127, 2006.

[15] M. Leber, A. Ivanišević, J. Borocki, M. Radišíc, and B. Ślusarczyk, "Fostering alliances with customers for the sustainable product creation," Sustain., vol. 10, no. 9, 2018.

[16] C. K. Prahalad and V. Ramaswamy, The Future of Competition: Co-Creating Unique Value with Customers. Boston, MA.: Harvard Business School Press, 2004.

[17] S. Vargo and R. Lusch, "Evolving to a New Dominant Logic for Marketing," J. Mark., vol. 68, no. 1, pp. 1-17, 2004.

[18] C. Panche-Vidales, S. P. Rojas-Berrio, and Ó. J. RobayoPinzón, "Evaluación de la lógica dominante del servicio para el caso de los seguros de automóviles en Colombia," Clio América, vol. 12, no. 23, pp. 62-72, 2018.

[19] S. Seran (Potra) and M. Izvercian, "Prosumer engagement in innovation strategies the prosumer creativity and focus 
model," Manag. Decis., vol. 52, no. 10, pp. 1968-1980, 2014.

[20] C. Huber, "Behavioral Insurance: Essays on the Influence of Ratings and Price Presentation on Consumer Evaluation, Risk Perception, and Financial Decision-Making," 2012, pp. 1-203.

[21] D. Kasirajan, "Health insurance an empirical study of consumer behavior in tuticorin district," Indian Streams Res. J., vol. 2, no. 3, pp. 1-6, 2012.

[22] A. Ulbinaite and Y. Le Moullec, "Towards an ABM-Based Framework for Investigating Consumer Behaviour in the Insurance Industry," Economics, vol. 89, no. 2, pp. 95-110, 2010.

[23] Wahyuningsih, "The Effect Of Customer Value On

Behavioral Intentions In Tourism Industry," Int. Res. J. Bus. Stud., vol. 5, no. 1, pp. 1-12, 2012.

[24] Y. Liu, Y. Chen, and G. H. Tzeng, "Identification of key factors in consumers' adoption behavior of intelligent medical terminals based on a hybrid modified MADM model for product improvement," Int. J. Med. Inform., vol. 105, pp. 68-82, 2017.

[25] J. Yoon, E.-Y. Jung, J.-D. Lee, S.-J. Kim, and M. Kim, “The effect of firm's routine on product evolution: The mobile phone," in PICMET 2014 - Portland International Center for Management of Engineering and Technology, Proceedings: Infrastructure and Service Integration, 2014, pp. 127-134.

[26] M. Kaptein, "Why Do Good People Sometimes Do Bad Things?: 52 Reflections on Ethics at Work," 2012.

[27] M. Kirova and L. Steinmann, "Sigma No. 6-13: Life insurance: focusing on the consumer," Zurich, Switzerland, 2013.

[28] S. Kumar and A. Seth, "The design of coordination and control mechanisms for managing joint venture-parent relationships," Strateg. Manag. J., vol. 19, no. 6, pp. 579599, 1998.

[29] V.-W. Mitchell and M. Greatorex, "Risk Perception and Reduction in the Purchase of Consumer Services," Serv. Ind. J., vol. 13, no. 4, pp. 179-200, 1993.

[30] A. C. Erasmus, E. Boshoff, and G. Rousseau, "Consumer Decision-Making Models within the Discipline of Consumer Science: a Critical Approach," J. Fam. Ecol. Consum. Sci., vol. 29, no. 1, pp. 82-90, 2001.

[31] J. Wei, M. Zhao, F. Wang, P. Cheng, and D. Zhao, "An Empirical Study of the Volkswagen Crisis in China: Customers' Information Processing and Behavioral Intentions," Risk Anal., vol. 36, no. 1, pp. 114-129, 2016.

[32] K. Schiffman, Consumer Behavior, 8th ed. Upper Saddle River, NJ: Prentice Hall, 2005.

[33] F. R. Dwyer, P. H. Schurr, and S. Oh, "Developing BuyerSeller Relationships," J. Mark., vol. 51, no. 2, pp. 11-27, 1987.

[34] R. M. Emerson, "Social Exchange Theory," Annu. Rev. Sociol., vol. 2, no. 1, pp. 335-362, 1976.

[35] I. Ajzen and M. Fishbein, "The prediction of behavioral intentions in a choice situation," J. Exp. Soc. Psychol., vol. 5, no. 4, pp. 400-416, 1969

[36] G. L. Shostack, "Breaking Free from Product Marketing," J. Mark., vol. 41, no. 2, pp. 73-80, 1977.

[37] T. Milner, "Influence of life events on consumer decision making: financial services and mature aged consumers in Australia," RMIT University, 2011.

[38] J. Creswell, Research design: qualitative, quantitative, and mixed methods approaches, 4th ed. Nebraska: University of Nebraska., 2014.

[39] J. Manson, Qualitative Researching, 2nd ed. Thousand Oaks, CA: Sage, 2002.

[40] J. Maxwell, "Using numbers in qualitative research," Qual. Inq., vol. 16, no. 6, pp. 475-482, 2010.

[41] M. Patton, Qualitative Research and Evaluation Methods, 3rd ed. Thousand Oaks, CA: Sage, 2002.

[42] N. Malhotra, Investigación de mercados: un enfoque aplicado. Cuidad de México: Pearson Educación, 2004.

[43] S. Schmidt, "In-Depth Interviews," in Qualitative Research Methods in Consumer Psychology, P. Hackett, Ed.

Routledge, Taylor \& Francis Group, 2016.

[44] K. Roulston and B. Martinez, "Recruitment and Sampling in Consumer Research," in Qualitative Research Methods in Consumer Psychology, P. Hackett, Ed. New York:
Routledge, Taylor \& Francis Group, 2016.

[45] K. Charmaz, Constructing Grounded Theory, 2nd ed. Los Angeles: Sage, 2014.

[46] A. Strauss and J. Corbin, Basics of Qualitative Research Techniques and Procedures for Developing Grounded Theory, Second., vol. 3. Thousand Oaks, California: Sage Publications, Inc., 2008. 


\section{Appendix 1: Guide for the in-depth interview}

Lifestyle in general: please tell me a little about your lifestyle:

-What is a typical day like in your life?

-What are your priorities in your life?

-What are your short, medium and long term goals?

-What worries you about the future?

-What do you do to minimize the risk?

-If I tell you insurance, what do you think?

-If I say life insurance, what do you think?

\section{Marketing Factors:}

- What factors related to marketing did you consider when purchasing your life insurance? (eg, positioning of insurance companies, the place where you acquired life insurance, promotions).

- How long did it take to select and buy your life insurance?

- How important was the price in the decision you made for your life insurance?

- How important is it to receive information about your life insurance through the media? Do you remember any type of advertising communication that has influenced your decision to purchase your life insurance?

- How much peace of mind does it give you to see advertising from your insurance company on television?

- Do you consider that having individual life insurance is a luxury? Why?

- Have you ever acquired any life insurance in any promotion of banks or insurance brokers? Why did you do it?

\section{Functional factors:}

Regarding the functional component of your life insurance:

- What factors did you consider when making the decision to buy life insurance?

- How important is the characteristics of a life insurance policy to you?

- Which were the most relevant in the process of buying your life insurance?

\section{Individual factors:}

- What does your life insurance mean to you?

- Does it have any emotional meaning for you?

- If you had to describe life insurance with a phrase or a word, what would you say?

- How important do you think life insurance can be for you? Why?

- How was the process of buying your life insurance policy?

- Had you defined what life insurance you were going to buy or did you analyze different options?

- How important was the choice of the insurance company?

- What made you finally decide on your life insurance?

- How important is your life insurance coverage?

-How important are the different life insurance coverage? Why?
-Do you remember the insured value of your life insurance policy?

\section{Social factors:}

- Does your circle of friends or acquaintances have life insurance?

- Do you think that your life insurance, according to coverage and amounts, speaks for you and represents what you want to project in front of other people?

- Do you have any life insurance abroad? In which country?

- Have you taken any insurance, on the recommendation of a friend or relative?

- Have you experienced situations of a family member or acquaintance that has led you to take your life insurance?

\section{Situational factors:}

- What was the decision that led you to make the decision to purchase life insurance? Why?

- How do you evaluate the process of buying your life insurance? How important is it that your insurance advisor guides you in the purchase of life insurance? Why?

- Did any person or group of people influence the decision to acquire your life insurance?

- After acquiring your life insurance, do you think this has been a good or a bad decision? Why?

- Do you currently feel calm with the insurance company that supports your life insurance?

- Are you currently calm with the support you receive from your insurance broker? Why?

- How do you evaluate the coverage you acquired with respect to the price? 